\title{
On the prediction of bolted single-lap composite joints
}

\author{
Álvaro Olmedo, Carlos Santiuste* \\ Department of Continuum Mechanics and Structural Analysis, University Carlos III of Madrid, Avda. de la Universidad 30,28911 Leganés, Madrid, Spain
}

\section{Keywords:}

Composite joint

Finite element modelling

Bolted joint

Aeronautical structures

\begin{abstract}
A B S T R A C T
A new set of failure criteria to predict composite failure in single lap bolted joints is proposed. The pres ent failure criteria are an extension of Chang Lessard criteria considering a three dimensional stress field and including out of plane failure modes. The advantage with respect to other three dimensional failure criteria is the consideration of non linear shear stress strain relationship. The failure criteria were imple mented in a finite element model and validated through comparison with experiments in literature. Stresses were calculated by a non linear finite element model developed in ABAQUS/Standard which con siders material and geometric nonlinearities. A progressive damage model was implemented in a USDFLD subroutine. The model predicted the effect of secondary bending and tightening torque showing an excel lent agreement with experimental results. Moreover, results were compared with those reported in lit erature using Hashin failure criteria. In addition, a parametric study was carried out to analyse the influence of friction coefficient and tightening torque.
\end{abstract}

\section{Introduction}

Composite structures are used extensively in aircraft structures because of their excellent mechanical properties combined with low density. Fastener joining is the most important method of assembling structural elements in the aerospace industry, due to its facility to assemble, disassemble and repair, and its tolerance to environmental effects.

For high responsibility applications on composite structures bolted joints should be carefully designed. The enhanced stress intensity factor at the surrounding of the hole and the weakness of the composite under out of plane loads, make the designing and assembly process more critical in the case of composite joints than in those based on metallic components. Structural safety should be ensured in aeronautical industry, thus the study of bolted joints in structural composite components have received considerable attention in both scientific literature and aeronautical standards [1 9 ].

A major goal of composite bolted joint research has been to determine the effect of various bolting parameters on the joint strength. The bolting parameters that have been studied include geometric factors [10], material properties [11], coefficients of fric tion [12], bolt shape [13], clearance [9], and torque [14,15]. These studies have provided strategies to design composite bolted joints avoiding catastrophic failure. The basic failure modes in bolted fibre reinforced materials are bearing, net tension and shear out

\footnotetext{
* Corresponding author. Tel.: +34 9162499 20; fax: +34 916249430.

E-mail address: csantius@ing.uc3m.es (C. Santiuste).
}

failures. From these failure modes only bearing damage produces a progressive failure, thus composite bolted joints are designed to fail under this mode. Bearing failure occurs in the material immediately adjacent to the contacting bolt surface due to primar ily compressive stresses and leading to a non linear behaviour of the composite plates [7].

The joint bearing strength depends on different parameters, such as: joint configuration, bolt torque, laminate and bolt materi als, laminate lay up, and temperature. The level of torque directly influences on the stress fields in both the bolt and the plates. An increment in the tightening torque has two important effects on the joint performance. The positive effect is the increment of fric tion forces that lead to increasing bearing strength. As was demon strated in $[14,16]$ for carbon/epoxy laminates, bearing strength grows when the clamping pressure is increased. On the other hand, the negative effect is that out of plane stresses can lead to a pre mature failure of the joint $[17,18]$. In consequence, the maximum value of torque is limited by standards.

Moreover, the effect of tightening torque and the through the thickness stress distribution are affected by the secondary bending phenomenon. The eccentric load path in single shear lap joints adds the issue of lateral deflection (or secondary bending) of the joint, which generates a non uniform contact pressure between the fasteners and the hole edge. A stress singularity is also intro duced when the bolt is tilted in its hole as the surface contact changes into a line contact [19]. The analyses of the stress field in single lap bolted joints have shown that secondary bending produce non uniform stress distributions through the thickness of composite laminates in the vicinity of the bolt hole $[5,20]$. 
The influence of torque and secondary bending on bearing strength has been investigated by several researchers by means of experimental studies, see for example $[6,8]$. However, due to the large range of different matrices, fibres and lay ups available to the designer, the use of purely empirical design procedures would be prohibitively expensive. It is important that all the aspects of joint design are well understood, the development of theoretical reliable models is required to optimise the prediction of bearing strength considering the effect of torque and secondary bending phenomenon.

The most accurate and general models to predict the onset of damage and ultimate failure of composite structures are based on the implementation of constitutive models developed in the context of continuum damage mechanics in finite element (FE) models. The development of a reliable FE model to predict bearing failure of bolted composite joint requires the implementation of failure criteria, the consideration of non linear stress strain rela tionship and a degradation procedure to reproduce the damage on the material.

For the sake of simplicity several authors have analysed pin loaded composite plates where tightening torque and secondary bending can be neglected. The most commonly used failure criteria to predict pin joints failure are those based on Chang Chang [21] and Chang Lessard [22] formulations that consider only in plane stresses. Several studies has demonstrated that non linear shear stress strain relationship must be considered to predict pin joints bearing strength [23 26].

Although 2D failure criteria can be applied to pin joint, the bolted joint problem is clearly 3D in nature [3]. Effects such as bolt clamp up and secondary bending are best accounted for by 3D models, while the bearing mode of failure is a $3 \mathrm{D}$ phenomenon, involving through thickness cracks and delaminations [2].

Failure criteria that consider out of plane stresses as Hashin [27] have been applied to predict bearing failure in double lap $[4,9]$ and bolted single lap joints $[28,29]$. These studies have proved the influence of out of plane stresses on bearing strength, however there is a lack of studies that consider both out of plane stresses and non linear shear stress strain relationship. The main goal of this work is the implementation of a new set of failure cri teria to predict bearing strength of bolted single lap composite joints. The proposed set of failure criteria is an extension of Chang Chang [21] and Chang Lessard [22] criteria including the effect of out of plane stresses.

The accuracy of failure criteria was validated through compari son with experimental data found in literature [13]. To analyse the influence of non linear shear stress strain relationship in the pre diction of bearing failure, the results were also compared with those obtained by Riccio using 3D Hashin failure criteria [29]. In addition, the effect of tightening torque and friction coefficient were analysed by means of a parametric study.

\section{Failure criteria}

Chang Lessard criteria were performed to predict damage in laminated composites subjected to compressive loading. The pur pose of the authors was the prediction of the in plane response of the laminates from initial loading to final collapse. Since in bolted single lap composite joints composite laminates are sub jected to out of plane stresses due to tightening torque and sec ondary bending effect, the proposed failure criteria includes the effect of both normal and shear out of plane stresses.

It is well known that the in plane shear deformation of compos ite plies exhibits non linear behaviour without causing damage. Hahn and Tsai [30] formulated the following non linear shear stress strain relationship using high order elasticity theory: $\gamma_{12} \quad \frac{1}{G_{12}} \tau_{12}+\alpha \tau_{12}^{2}$

where $G_{12}, \tau_{12}$, and $\gamma_{12}$ are, respectively, the in plane shear modu lus, shear stress, and shear strain. $\alpha$ is a constant parameter which is determined experimentally.

Due to the planar structure of composite laminates, the non lin ear response is difficult to measure under out of plane shear stres ses. However, since non linear response of composite is mainly dominated by matrix behaviour, the same assumption can be adopted for out of plane shear deformations:

$\gamma_{13} \quad \frac{1}{G_{12}} \tau_{13}+\alpha \tau_{13}^{3}$

$\gamma_{23} \quad \frac{1}{G_{23}} \tau_{23}+\alpha \tau_{23}^{3}$

where $G_{13}$ and $G_{23}$ are the shear moduli, $\tau_{13}$ and $\tau_{23}$ the shear stres ses, and $\gamma_{13}$ and $\gamma_{23}$ the shear strains.

Chang Lessard criteria consider four failure modes: matrix crushing, matrix cracking, fibre matrix shearing failure, and fibre failure. The proposed extension of Chang Lessard criteria consists in the inclusion of out of plane shear stresses in the formulations of these four failure criteria, and the consideration of two new fail ure modes: out of plane matrix crushing and delamination.

\subsection{Matrix crushing}

Chang Lessard criteria consider matrix crushing failure $\left(\sigma_{2}<0\right)$ due to compressive transverse stress and in plane stress, Eq. (4). The present failure criterion includes the contribution of out of plane shear stress, Eq. (5).

$\left(\frac{\sigma_{2}}{Y_{C}}\right)^{2}+\frac{\int_{0}^{\gamma_{12}} \tau_{12} d \gamma_{12}}{\int_{0}^{\gamma_{12}^{M}} \tau_{12} d \gamma_{12}} \quad e_{m c 2}^{2}$

$\left(\frac{\sigma_{2}}{Y_{C}}\right)^{2}+\frac{\int_{0}^{\gamma_{12}} \tau_{12} d \gamma_{12}}{\int_{0}^{\gamma_{12}^{M}} \tau_{12} d \gamma_{12}}+\frac{\int_{0}^{\gamma_{23}} \tau_{23} d \gamma_{23}}{\int_{0}^{\gamma_{23}^{M}} \tau_{23} d \gamma_{23}} \quad e_{m c 2}^{2}$

where $\sigma_{2}$ is the normal stress in transverse direction, $Y_{C}$ is the trans verse compressive strength, and $\gamma_{12}^{M}$ and $\gamma_{23}^{M}$ are the ultimate shear strains.

In any of the elements, when the criterion is satisfied $\left(e_{m c}>1\right)$ the composite fails by matrix crushing. By introducing the shear stress strain relationships, Eqs. (1) and (3), into Eq. (5), matrix crushing failure criterion yields:

$\left(\frac{\sigma_{2}}{Y_{C}}\right)^{2}+\frac{\frac{\tau_{12}^{2}}{2 G_{12}}+\frac{3}{4} \alpha \tau_{12}^{4}}{\frac{S_{12}^{2}}{2 G_{12}}+\frac{3}{4} \alpha S_{12}^{4}}+\frac{\frac{\tau_{23}^{2}}{2 G_{23}}+\frac{3}{4} \alpha \tau_{23}^{4}}{\frac{S_{23}^{2}}{2 G_{23}}+\frac{3}{4} \alpha S_{23}^{4}} \quad e_{m c 2}^{2}$

where $S_{12}$ and $S_{23}$ are the in plane and out of plane shear strengths.

For composites with linear elastic behaviour $(\alpha=0)$ it should be notice that Eq. (6) can be reduced to:

$\left(\frac{\sigma_{2}}{Y_{C}}\right)^{2}+\left(\frac{\tau_{12}}{S_{12}}\right)^{2}+\left(\frac{\tau_{23}}{S_{23}}\right)^{2} \quad e_{m c 2}^{2}$

Additionally, a matrix crushing failure criterion is added to con sider out of plane compressive normal stresses $\left(\sigma_{3}<0\right)$, Eq. (8). This failure criterion can take into account the damage produced by tightening torque.

$\left(\frac{\sigma_{3}}{Z_{C}}\right)^{2}+\frac{\frac{\tau_{13}^{2}}{2 G_{13}}+\frac{3}{4} \alpha \tau_{13}^{4}}{\frac{S_{13}^{2}}{2 G_{13}}+\frac{3}{4} \alpha S_{13}^{4}}+\frac{\frac{\tau_{23}^{2}}{2 G_{23}}+\frac{3}{4} \alpha \tau_{23}^{4}}{\frac{S_{23}^{2}}{2 G_{23}}+\frac{3}{4} \alpha S_{23}^{4}} \quad e_{m c 3}^{2}$

where $\sigma_{3}$ is the out of plane normal stress, $Z_{C}$ is the out of plane compressive strength and $S_{13}$ is the out of plane shear strength.For linear elastic composites $(\alpha=0)$ Eq. (8) can be reduced to: 
$\left(\frac{\sigma_{3}}{Z_{C}}\right)^{2}+\left(\frac{\tau_{13}}{S_{13}}\right)^{2}+\left(\frac{\tau_{23}}{S_{23}}\right)^{2} \quad e_{m c 3}^{2}$

\subsection{Matrix cracking}

The Chang Lessard criterion for in plane tensile matrix crack ing failure $\left(\sigma_{2}>0\right)$ considers normal transverse stress and in plane shear stress. In the present failure criterion the contribution of out of plane shear stress is also considered, Eq. (10).

$\left(\frac{\sigma_{2}}{Y_{T}}\right)^{2}+\frac{\int_{0}^{\gamma_{12}} \tau_{12} d \gamma_{12}}{\int_{0}^{\gamma_{12}^{M}} \tau_{12} d \gamma_{12}}+\frac{\int_{0}^{\gamma_{23}} \tau_{23} d \gamma_{23}}{\int_{0}^{\gamma_{23}^{M}} \tau_{23} d \gamma_{23}} \quad e_{m t 2}^{2}$

where $Y_{T}$ is the transverse tensile strength.

When the criterion is satisfied $\left(e_{m t}>1\right)$ the composite fails by matrix cracking. By introducing the shear stress strain relation ships, Eqs. (1) and (3), into Eq. (10), matrix cracking failure crite rion yields:

$\left(\frac{\sigma_{2}}{Y_{T}}\right)^{2}+\frac{\frac{\tau_{12}^{2}}{2 G_{12}}+\frac{3}{4} \alpha \tau_{12}^{4}}{\frac{S_{12}^{2}}{2 G_{12}}+\frac{3}{4} \alpha S_{12}^{4}}+\frac{\frac{\tau_{23}^{2}}{2 G_{23}}+\frac{3}{4} \alpha \tau_{23}^{4}}{\frac{S_{23}^{2}}{2 G_{23}}+\frac{3}{4} \alpha S_{23}^{4}} \quad e_{m t 2}^{2}$

For linear elastic composites ( $\alpha=0$ ) Eq. (11) can be reduced to:

$\left(\frac{\sigma_{2}}{Y_{T}}\right)^{2}+\left(\frac{\tau_{12}}{S_{12}}\right)^{2}+\left(\frac{\tau_{23}}{S_{23}}\right)^{2} \quad e_{m t 2}^{2}$

Additionally, a matrix cracking failure criterion is added to con sider out of plane tensile normal stresses $\left(\sigma_{3}>0\right)$, Eq. (13). This failure criterion can be used to predict delamination onset,

$\left(\frac{\sigma_{3}}{Y_{T}}\right)^{2}+\frac{\frac{\tau_{13}^{2}}{2 G_{13}}+\frac{3}{4} \alpha \tau_{13}^{4}}{\frac{S_{13}^{2}}{2 G_{13}}+\frac{3}{4} \alpha S_{13}^{4}}+\frac{\frac{\tau_{23}^{2}}{2 G_{23}}+\frac{3}{4} \alpha \tau_{23}^{4}}{\frac{S_{23}^{2}}{2 G_{23}}+\frac{3}{4} \alpha S_{23}^{4}} \quad e_{m t 3}^{2}$

where $Z_{T}$ is the out of plane tensile strength.For linear elastic com posites $(\alpha=0)$ Eq. (13) can be reduced to:

$\left(\frac{\sigma_{3}}{Z_{T}}\right)^{2}+\left(\frac{\tau_{13}}{S_{13}}\right)^{2}+\left(\frac{\tau_{23}}{S_{23}}\right)^{2} \quad e_{m t 3}^{2}$

\subsection{Fibre matrix shearing failure}

For predicting fibre matrix shearing failure $\left(\sigma_{1}<0\right)$, Chang Les sard criterion considers the effect of normal stress in fibre direction and in plane shear stress. The present failure criterion includes the contribution of out of plane shear stresses, Eq. (15).

$\left(\frac{\sigma_{1}}{X_{C}}\right)^{2}+\frac{\int_{0}^{\gamma_{12}} \tau_{12} d \gamma_{12}}{\int_{0}^{\gamma_{12}^{M}} \tau_{12} d \gamma_{12}}+\frac{\int_{0}^{\gamma_{13}} \tau_{13} d \gamma_{13}}{\int_{0}^{\gamma_{13}^{M}} \tau_{13} d \gamma_{13}} e_{s}^{2}$

where $\sigma_{1}$ is the normal stress in fibre direction and $X_{C}$ the fibre compressive strength.

By introducing the shear stress strain relationships, Eqs. (1) and (2), into Eq. (15), the shear fibre matrix failure criterion yields:

$\left(\frac{\sigma_{1}}{X_{C}}\right)^{2}+\frac{\frac{\tau_{12}^{2}}{2 G_{12}}+\frac{3}{4} \alpha \tau_{12}^{4}}{\frac{S_{12}^{2}}{2 G_{12}}+\frac{3}{4} \alpha S_{12}^{4}}+\frac{\frac{\tau_{13}^{2}}{2 G_{13}}+\frac{3}{4} \alpha \tau_{13}^{4}}{\frac{S_{13}^{2}}{2 G_{13}}+\frac{3}{4} \alpha S_{13}^{4}} \quad e_{s}^{2}$

Once again, for composites with linear elastic behaviour $(\alpha=0)$ Eq. (16) can be reduced to:

$\left(\frac{\sigma_{1}}{X_{C}}\right)^{2}+\left(\frac{\tau_{12}}{S_{12}}\right)^{2}+\left(\frac{\tau_{12}}{S_{12}}\right)^{2} \quad e_{s}^{2}$

\subsection{Fibre failure}

Chang Lessard fibre failure criterion considers only compres sive loads, thus it is based on the fibre buckling strength, Eq. (18). To consider the possibility of tensile loads, the present model includes a tensile fibre failure criterion based on Chang Chang fail ure criteria, Eq. (19).

$\frac{\sigma_{1}}{X_{C}} \quad e_{f c}^{2}$

$\left(\frac{\sigma_{1}}{X_{T}}\right)^{2}+\frac{\int_{0}^{\gamma_{12}} \tau_{12} d \gamma_{12}}{\int_{0}^{\gamma_{12}^{M}} \tau_{12} d \gamma_{12}}+\frac{\int_{0}^{\gamma_{13}} \tau_{13} d \gamma_{13}}{\int_{0}^{\gamma_{13}^{M}} \tau_{13} d \gamma_{13}} \quad e_{f t}^{2}$

where $X_{T}$ the fibre tensile strength.

By introducing the shear stress strain relationships, Eqs. (1) and (2), into Eq. (19), the tensile fibre failure criterion yields:

$\left(\frac{\sigma_{1}}{X_{T}}\right)^{2}+\frac{\frac{\tau_{12}^{2}}{2 G_{12}}+\frac{3}{4} \alpha \tau_{12}^{4}}{\frac{S_{12}^{2}}{2 G_{12}}+\frac{3}{4} \alpha S_{12}^{4}}+\frac{\frac{\tau_{13}^{2}}{2 G_{13}}+\frac{3}{4} \alpha \tau_{13}^{4}}{\frac{S_{13}^{2}}{2 G_{13}}+\frac{3}{4} \alpha S_{13}^{4}} \quad e_{f t}^{2}$

For composites with linear elastic behaviour $(\alpha=0)$ Eq. (20) can be reduced to:

$\left(\frac{\sigma_{1}}{X_{T}}\right)^{2}+\left(\frac{\tau_{12}}{S_{12}}\right)^{2}+\left(\frac{\tau_{13}}{S_{13}}\right)^{2} \quad e_{f t}^{2}$

\section{Numerical model}

A FE numerical model reproducing a bolted single lap joint according to [13] was developed using the ABAQUS/Standard code considering non linear stress calculation due to large displace ments and composite material behaviour. In addition, Riccio devel oped a FE model of these tests including a progressive damage model based on Hashin failure criteria [29]. Therefore, the results predicted by the present model could be compared with those pre dicted by a classical 3D failure criteria such as Hashin.

Single lap composite to aluminium joints were manufactured by using carbon epoxy composite HTA 7/6376 and aluminium AA7475 T76 for plates and titanium 6Al114VSTA for bolts and nuts. The mechanical properties of these materials are described in Tables 1 and 2 . The composite lay up was $\left[(0 / \pm 45 / 90)_{2}\right]_{S}$ and the geometrical description of the single lap specimen is given in Fig. 1. Bolt, nut and washer were considered as a titanium single solid, and the relative displacements between bolt and nut were implemented through a bolt load available in Abaqus/Standard.

Table 1

Mechanical properties of carbon-epoxy composite HTA 7/6376.

\begin{tabular}{ll}
\hline Carbon epoxy HTA 7/6376 & \\
\hline Longitudinal modulus, $E_{1}(\mathrm{GPa})$ & 145 \\
Transverse modulus, $E_{2}(\mathrm{GPa})$ & 10.3 \\
Transverse modulus, $E_{3}(\mathrm{GPa})$ & 11.1 \\
In-plane shear modulus, $G_{12}(\mathrm{GPa})$ & 5.3 \\
Out-of-plane shear modulus, $G_{13}(\mathrm{GPa})$ & 5.27 \\
Out-of-plane shear modulus, $G_{23}(\mathrm{GPa})$ & 3.95 \\
Major Poisson's ratio, $v_{12}$ & 0.3 \\
Through thickness Poisson's ratio, $v_{23}$ & 0.5 \\
Through thickness Poisson's ratio, $v_{13}$ & 0.5 \\
Longitudinal tensile strength, $X_{T}(\mathrm{MPa})$ & 2250 \\
Longitudinal compressive strength, $X_{c}(\mathrm{MPa})$ & 1600 \\
Transverse tensile strength, $Y_{T}(\mathrm{MPa})$ & 64 \\
Transverse compressive strength, $Y_{c}(\mathrm{MPa})$ & 290 \\
Longitudinal tensile strength, $Z_{T}(\mathrm{MPa})$ & 50 \\
Longitudinal compressive strength, $Z_{C}(\mathrm{MPa})$ & 300 \\
In-plane shear strength, $S_{12}(\mathrm{MPa})$ & 120 \\
In-plane shear strength, $S_{13}(\mathrm{MPa})$ & 120 \\
Out-of-plane shear strength, $S_{23}(\mathrm{MPa})$ & 50 \\
\hline
\end{tabular}


Table 2

Mechanical properties of metallic components.

\begin{tabular}{lll}
\hline & Aluminium AA7475-T76 & Titanium 6Al114VSTA \\
\hline Young's modulus, $E(\mathrm{GPa})$ & 69 & 110 \\
Poisson's ratio, $v$ & 0.28 & 0.29 \\
Yield stress, $\sigma_{y}(\mathrm{MPa})$ & 451 & 1030 \\
\hline
\end{tabular}

Thus three solids were used in the FE model: composite plate, alu minium plate, and the bolt nut washer solid.

\subsection{Contact and boundary conditions}

Contact interactions were modelled using surface based contact considering the linear penalty method. Five contact interactions were defined between the three solids; the composite plate was in contact with aluminium plate, bolt head and bolt shank; and aluminium plate was in contact with nut surface and bolt shank.

The effect of pressure on friction coefficient was neglected, and a constant value of friction coefficient equal to 0.114 was imple mented. This friction coefficient was obtained from the work of Herrington and Sabbaghian [31] were friction coefficients between composite plates and the metallic components of the joint were analysed. This value has been used also by other researchers [8].

The loading path was divided into two steps. In the first step, the free ends of aluminium and composite plates were clamped and tightening torque was applied as a bolt load. The bolt load was implemented in the FE model introducing a pre tension condi tion. This pre tensioning is simulated in Abaqus/Standard by add ing a "cutting surface" in the bolt and subjecting it to a normal load. By modifying the elements on one side of the surface, Aba qus/Standard can automatically adjust the length of the bolt at the pre tension section to achieve the prescribed amount of pre tension. The relation between the applied torque $\tau$ and the normal pressure $p_{w}$, acting on the laminate under the washer is [32]:

$$
p_{w} \frac{\tau}{k \cdot d \cdot \frac{\pi}{4} \cdot\left(D^{2} d^{2}\right)}
$$

where $d$ is the bolt diameter, $k$ is the torque coefficient usually taken as 0.2 [33], and $D$ is the washer diameter. Thus bolt load can be calculated as:

$F_{\text {bolt }} \frac{\tau}{k \cdot d}$

In the second step, the free end of aluminium plate remained clamped, bolt length was fixed simulating the conservation of tight ening torque, and the tension load was applied at the free end of composite plate. The load was applied by imposing only a longitu dinal displacement, thus plates were free to rotate leading to sec ondary bending phenomenon.

Convergence problems due to the rigid body motions (related to possible initial no contact conditions) have been solved by introducing elastic springs with a very low stiffness between a fixed point in space and the unconstrained subcomponents of the joint, see Fig. 2.

\subsection{Mesh}

The aim of the model is to analyse not only the force displace ment relationship, but also the failure modes. Thus a mesh refine ment process was carried out to assure that results are not dependent upon the elements size. Successive space discretizations were compared varying the element size in the surrounding of the hole from $0.15 \mathrm{~mm}$ to $0.5 \mathrm{~mm}$. The characteristic element size in the final mesh was $0.26 \mathrm{~mm}$, enough to provide accurate results without an expensive computational cost. A total of 41,850 eight node brick elements with reduced integration (C3D8R in Abaqus) were employed to model the composite joint, Fig. 3. Composite plate was modelled with 30,720 elements, aluminium plate with 5120 elements, and 6010 elements were used to model the bolt and the nut.

\subsection{Material model}

The proposed failure criteria were used to predict the failure of composite plate. A progressive damage model was implemented using a USDFLD subroutine in Abaqus/Standard which allows material properties to be a direct function of predefined field vari ables. Stresses are called into the subroutine at the start of the cur rent increment and used to evaluate failure criteria. Once the failure criteria are met, the field variables are updated and used to reduce the elastic properties according to the corresponding fail ure mode, Table 3.

When material properties are degraded at a point, the load re distributes to other points, which could then fail themselves. It is therefore necessary to iterate at the same load level when mate rial properties change to determine if other material points undergo failure. The accuracy of the results when using USDFLD depends on the size of the time increment. Thus, in this analysis very small load steps were used. On the other hand, isotropic hardening model was used to model the plastic behaviour of the metallic components.
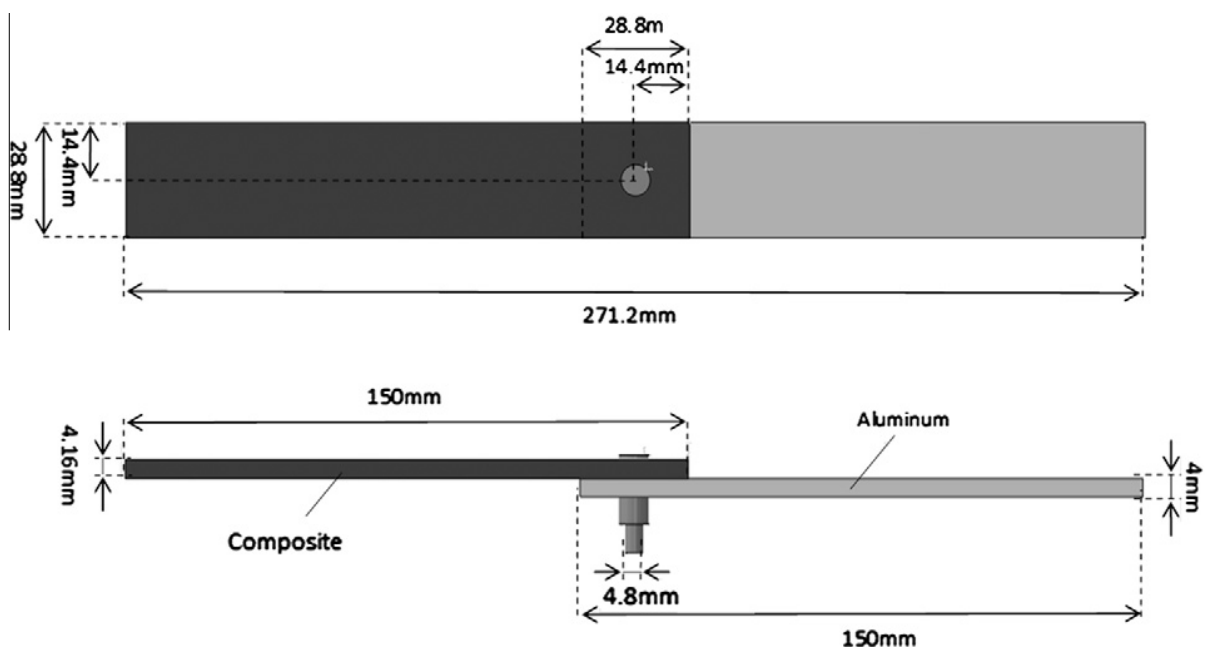

Fig. 1. Geometrical description of the single-lap-joint. 


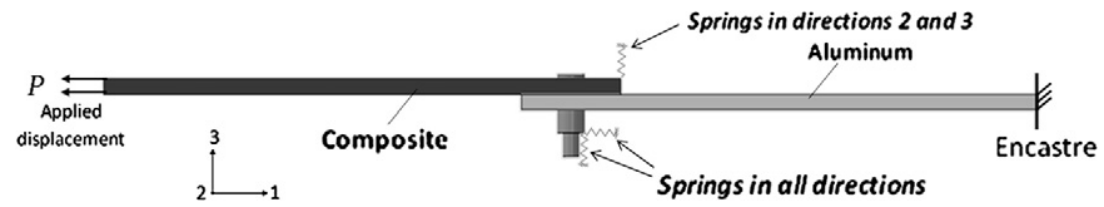

Fig. 2. Boundary conditions.

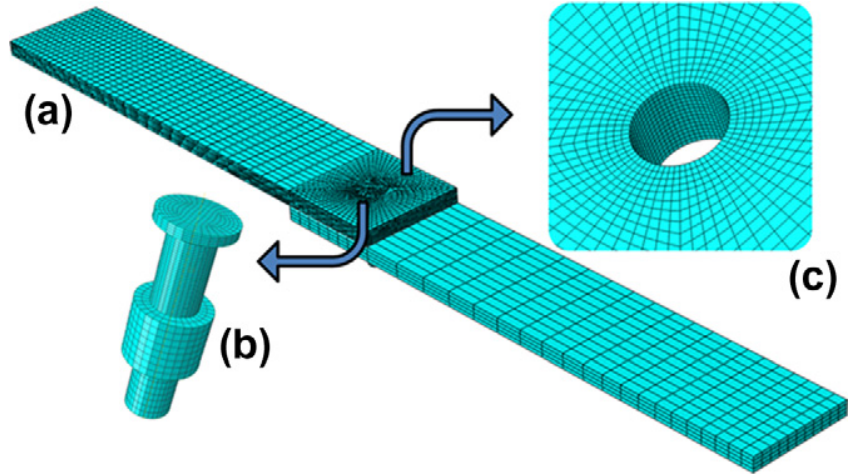

Fig. 3. FE model mesh. (a) complete model. (b) bolt and nut, (c) mesh detail.

Table 3

Material properties degraded according to each failure criterion.

\begin{tabular}{llllllllll}
\hline Failure mode & $E_{1}$ & $E_{2}$ & $E_{3}$ & $G_{12}$ & $G_{13}$ & $G_{23}$ & $v_{12}$ & $v_{13}$ & $v_{23}$ \\
\hline Fibre tension & 0.14 & 0.4 & 0.4 & 0.25 & 0.25 & 0.2 & 0 & 0 & 0 \\
Fibre compression & 0.14 & 0.4 & 0.4 & 0.25 & 0.25 & 0.2 & 0 & 0 & 0 \\
Fibre-Matrix shear & & & & 0.25 & 0.25 & & 0 & 0 & \\
Matrix tension & & 0.4 & 0.4 & & & 0.2 & 0 & 0 & 0 \\
Matrix compression & & 0.4 & 0.4 & & & 0.2 & 0 & 0 & 0 \\
\hline
\end{tabular}

\section{Results and discussion}

\subsection{Model validation}

The obtained numerical results were compared with the exper imental data from literature [13] to validate the proposed failure criteria. Moreover, the numerical predictions were compared with those of Riccio [29] who implemented a 3D progressive damage FE model, based on the Hashin failure criteria. In Fig. 4 the compari son between experimental and numerical load displacement curves are shown. An excellent agreement between numerical pre diction and experimental data was found in both stiffness and bearing strength. The proposed failure criteria predicted bearing failure for a load of $11,601 \mathrm{~N}$, similar to the experimental results: $10,860 \mathrm{~N}$ and $11,230 \mathrm{~N}$. Moreover the present model can reproduce the non linearity of the load displacement curve and the progres sive failure of the joint.

Riccio progressive damage model showed a non linear load displacement relationship due to the degradation of mechanical properties. However, Hashin failure criteria overestimated the stiffness and the bearing strength of the joint. The maximum load predicted by the present model was lower than that predicted by Riccio because Hashin failure criteria does not consider non linear shear stress strain relationship. There are also other reasons that can contribute to these discrepancies as the different degradation procedure and the plastic model for metallic elements.

\subsection{Damage mechanisms}

In addition, FE model was used to analyse the damage mecha nisms that produced the failure of the composite plate. The values

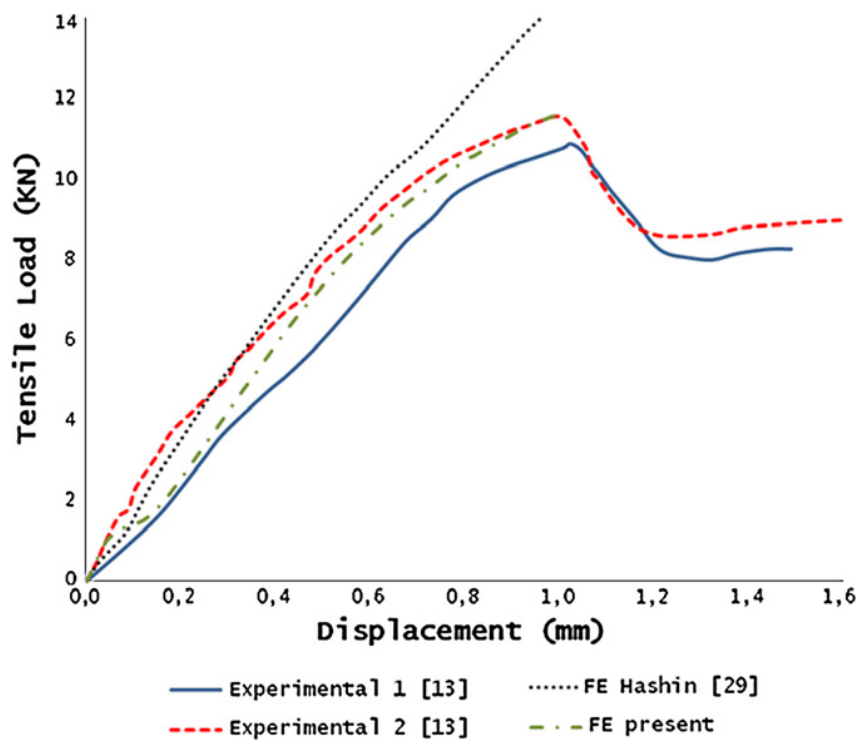

Fig. 4. Load-displacement curves. Numerical predictions and experimental results.

of the failure criteria in the surroundings of the hole when bearing failure occurs are plot in Figs. 5 and 6. Fig. 5 shows the top surface of the composite plate in contact with the bolt head, while Fig. 6 shows the bottom surface in contact with the aluminium plate. Matrix failure was mainly produced by compressive stresses thus, for sake of simplicity, only matrix crushing failure criterion is plot ted. The through the thickness distribution of the failure criteria reveals that the single lap composite joint is a 3D problem in nature.

The maximum values of fibre failure criterion were located at the lower plies of the laminate. Due to the secondary bending effect, the compressive load exerted by the bolt shank was concen trated on lower plies, thus the through the thickness distribution of the fibre failure criterion was non uniform. Moreover, plies ori ented in the longitudinal direction presented higher values of fibre failure criterion.

The maximum values of fibre matrix shearing failure criterion were also located mainly at the lower plies due to secondary bend ing. For the same reason high values of fibre matrix shearing fail ure also appeared in the top ply due to the compressive load exerted by the bolt head.

The distribution of the matrix failure criterion in transverse direction was dominated by secondary bending too. The compres sive load exerted by the bolt shank was concentrated on the lower plies. On the other hand, the top ply was damaged due to the com pressive load applied by the bolt head. This pressure applied by the bolt head was non uniform due to secondary bending.

The field of the matrix failure criterion in direction 3 revealed the weight of the tightening torque. In the surroundings of the hole, the matrix was damage due to the compressive load applied by the bolt head. Tightening torque produced matrix crushing in the com posite plate and a degradation of the mechanical properties. Thus the consideration of the damage induced by the out of plane 


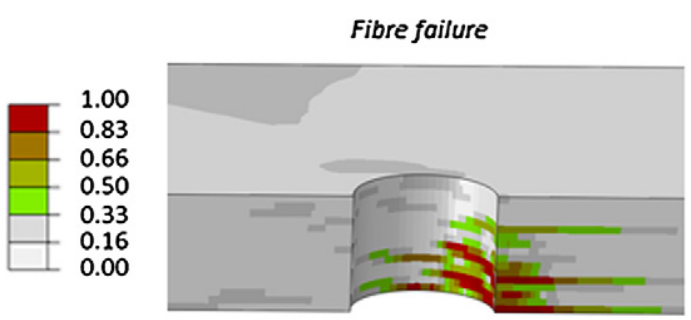

Fibre-Matrix shearing failure
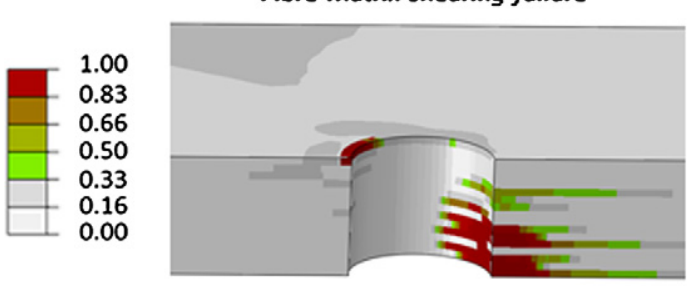

Matrix failure in direction 2
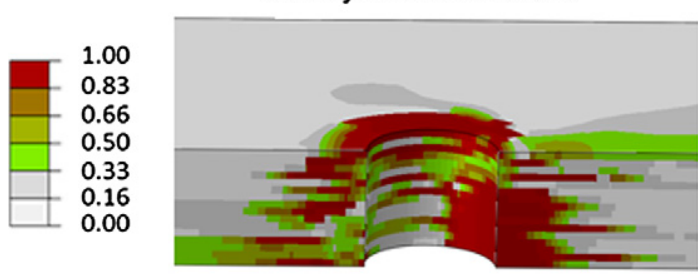

Matrix failure in direction 3
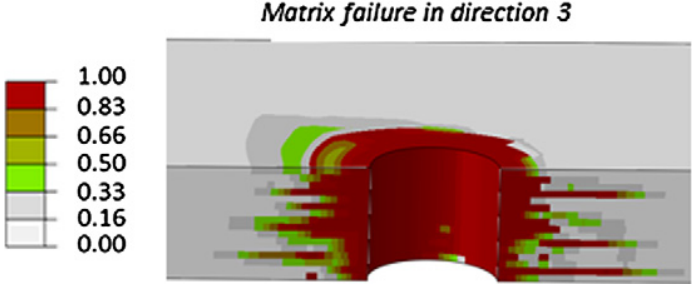

Fig. 5. Failure criteria in composite plate. Top view.

stresses is required to get an accurate prediction of the progressive bearing failure in bolted single lap composite joints.

\subsection{Effect of friction coefficient}

A parametric study was carried out to verify the capability of the FE model to reproduce the influence of friction coefficient and tightening torque observed in experimental results $[28,15]$. Fig. 7 shows the load displacement curves for different friction coefficients. It is well know that an increment in friction coefficient between plates increases the joint strength [28]. The numerical FE model can reproduce this effect observed in experimental tests re ported in literature. This effect was mainly observed for small dis placements because, once the relative displacements are higher that the clearance between bolt and hole, the slope of the load dis placement curve is non dependent on the friction coefficient.

\subsection{Effect of torque}

Figs. 8 and 9 show the load displacement curves for different torque tightening. In Fig. 8 the friction coefficient is equal to 0.1 and load displacement curves show that, with this low value of friction coefficient, the load necessary to produce a relative dis placement between plates is very low. In this case, an increment in the tightening torque does not produce a significant increase in friction forces; on the other hand a high torque can induce ma

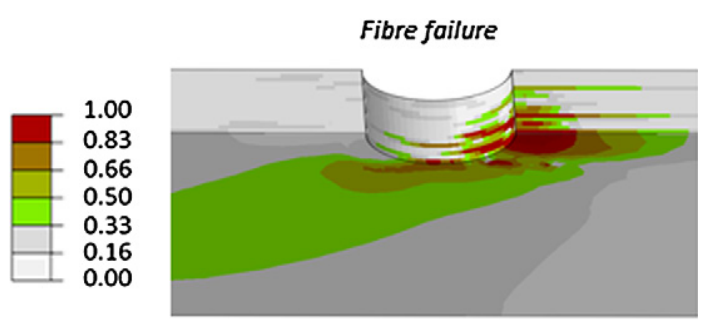

Fibre-Matrix shearing failure
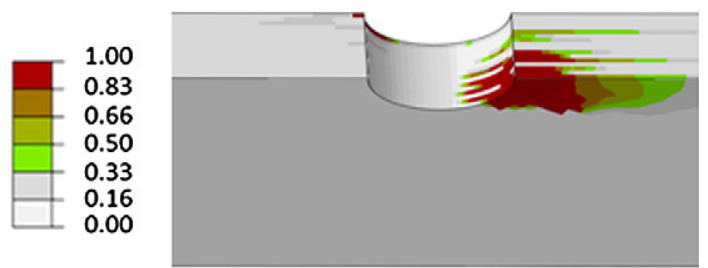

Matrix failure in direction 2

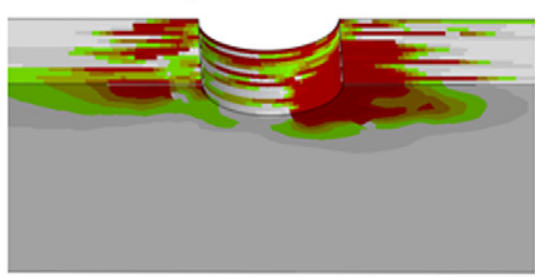

Matrix failure in direction 3
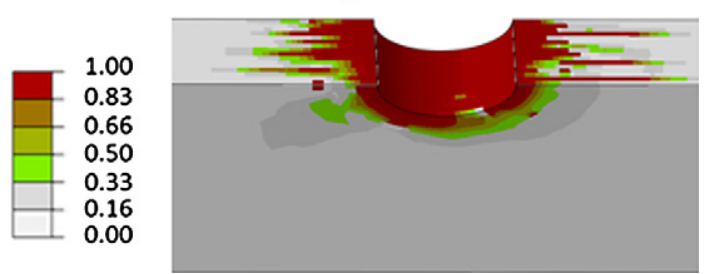

Fig. 6. Failure criteria in composite plate. Bottom view.

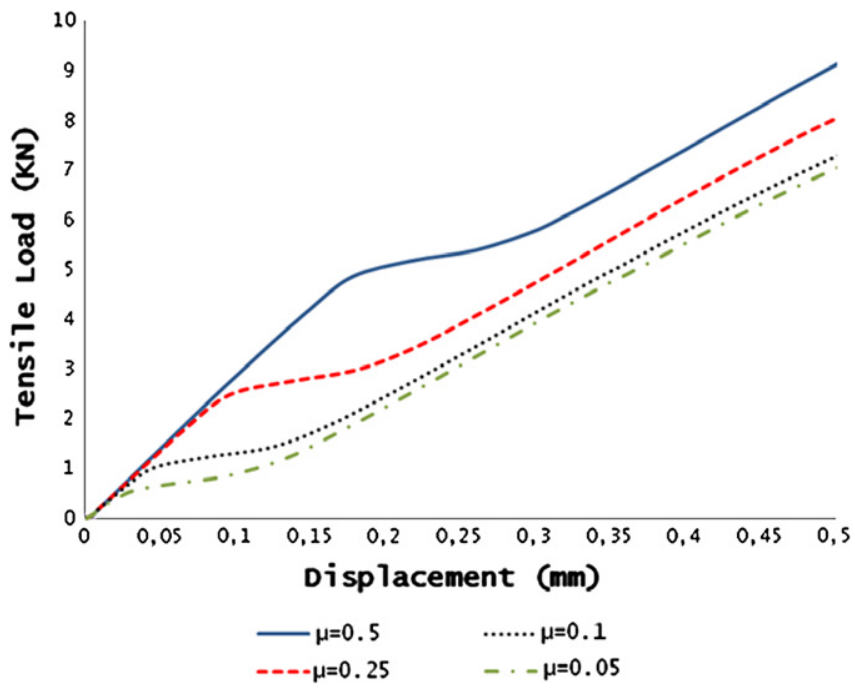

Fig. 7. Load-displacement curves. Influence of friction coefficient.

trix crushing in the composite plate. Thus for low values of friction coefficient an increment in the tightening torque cannot be used to increase the joint strength. 


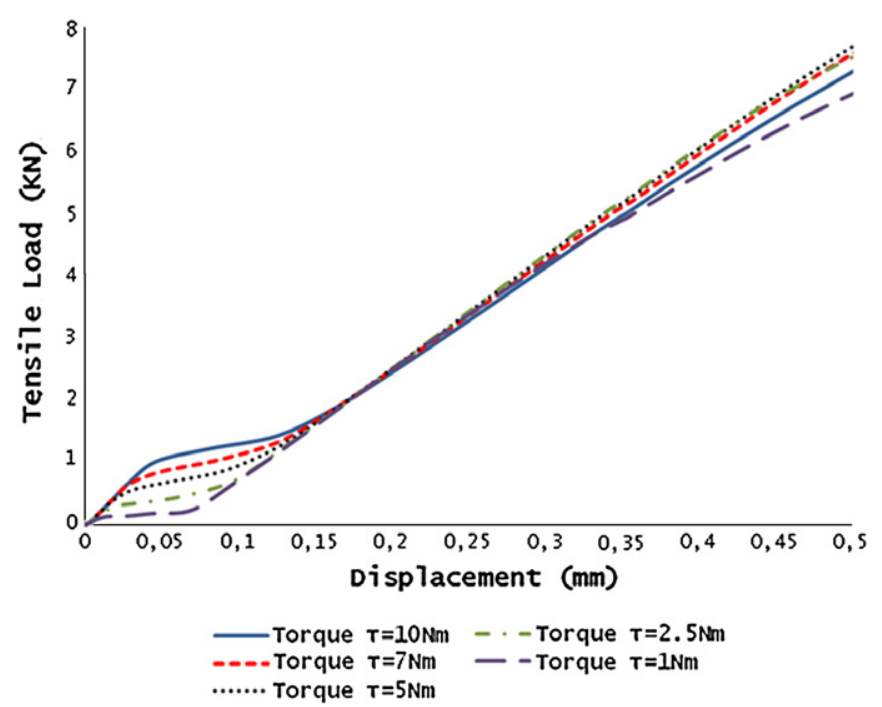

Fig. 8. Load-displacement curves. Friction coefficient equal to 0.1 . Influence of torque.

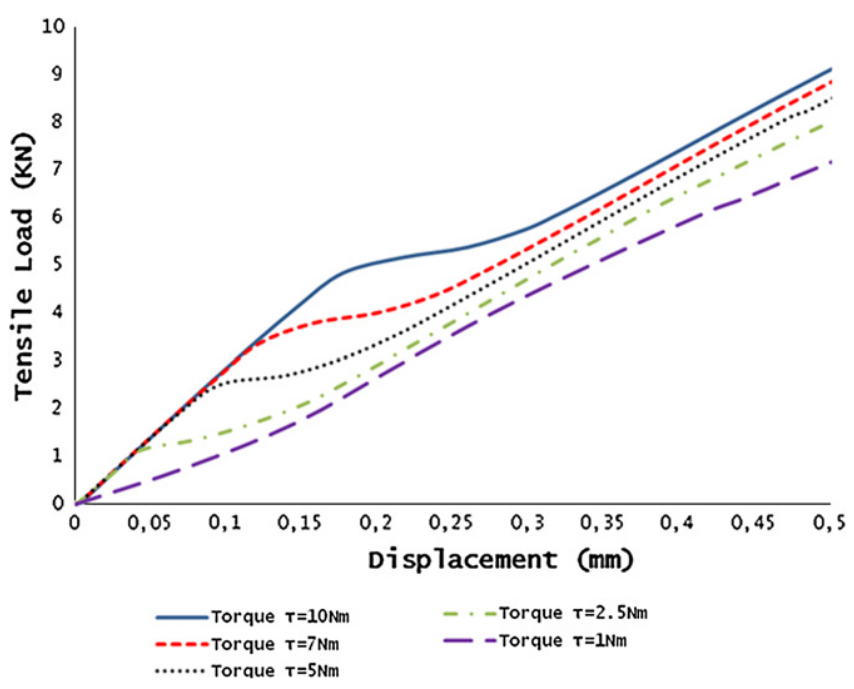

Fig. 9. Load-displacement curves. Friction coefficient equal to 0.5. Influence of torque.

Fig. 9 shows the load displacement curves with a friction coef ficient equal to 0.5 . With this high friction coefficient friction forces play a major role in bearing strength. An increase in tightening tor que leads to an increase in the joint stiffness according to the re sults reported in [34]. These results revealed than the maximum torque imposed by standards to prevent damage should be related to the friction coefficients.

\section{Conclusions}

A new set of failure criteria is proposed to predict composite failure in bolted joints. The present failure criteria include out of plane shear stresses in the formulations of the four failure criteria proposed by Chang Lessard and the consideration of two new fail ure modes: out of plane matrix cracking and delamination.

The advantages of the present failure criteria with respect to Chang Lessard criteria are the consideration of a 3D stress field and the prediction of out of plane failure modes as delamination. The main advantage with respect to others 3D failure criteria as Hashin is the inclusion of non linear shear stress strain relation ship. These advantages are especially useful to predict bearing fail ure in bolted single lap composite joints because the present model can take into account the out of plane stresses produced by torque tightening and the 3D stress field induced by secondary bending.

The accuracy of failure criteria was validated through compari son with experiments in literature [13]. The experiments consisted in the analysis of bolted single lap composite joints strength where results were influenced by secondary bending and torque tighten ing. A FE model was developed considering non linear stress calculation due to large displacements and composite material behaviour in ABAQUS/Standard. A progressive damage model was implemented using a USDFLD subroutine which allows material properties to be a direct function of failure criteria. If a failure cri terion is verified, the elastic properties were degraded according to the corresponding failure mode. A convergence study including mesh refinement was also carried out to investigate the influence of discretization on the stress distribution in the vicinity of the hole. Results from the numerical simulation were compared with experimental data. The agreement was excellent in terms of joint stiffness and bearing strength. Moreover, the present model was able to reproduce the non linearity of the load displacement curve and the progressive failure of the joint.

The results were also compared with those obtained by Riccio [29] using classical 3D failure criteria as Hashin. The maximum load predicted by the present failure criteria was lower than that predicted by Hashin because of the consideration of non linear shear stress strain relationship. Hashin criteria overestimated the stiffness and the bearing strength of the joint.

The analysis of failure mechanisms showed that secondary bending effect leads to a non uniform through the thickness dis tribution. Fibre bucking, fibre matrix shearing failure and in plane matrix crushing were located at the lower plies producing a pro gressive failure of the joint. Out of plane matrix crushing was distributed on the surface under bolt head and produced a degra dation of mechanical properties. Therefore the consideration of 3D stress field including out of plane stresses is necessary to pre dict bearing failure in bolted single lap composite joints.

In addition, a parametric study was carried out to analyse the influence of friction coefficient and tightening torque. The study showed that an increment in friction coefficient between plates leads to an increase in friction forces and joint stiffness. The effect of torque depends on the friction coefficient. For low values of fric tion coefficient the effect of an increment in tightening torque can be harmful. However, for moderate high values of friction coeffi cient the joint stiffness can be increased by increasing the tighten ing torque.

\section{Acknowledgement}

The authors are indebted to the Spanish Comisión Interministe rial de Ciencia y Tecnología (TRA2010 19573) for the financial sup port of this work.

\section{References}

[1] ASTM D5961. Standard test method for bearing response of polymer matrix composite laminates; 2005.

[2] Camanho PP, Matthews FL. Stress analysis and strength prediction of mechanically fastened joints in FRP: a review. Compos Part A: Appl Sci Manuf 1997;28(6):529-47.

[3] Camanho PP, Bowron S, Matthews FL. Failure mechanisms in bolted FRP. J Reinf Plast Compos 1998;17(3):205-33.

[4] Camanho PP, Matthews FL. A progressive damage model for mechanically fastened joints in composite laminates. J Compos Mater 1999;33(24):2248-80.

[5] Ireman T. Three-dimensional stress analysis of bolted single-lap composite joints. Compos Struct 1998;43(3):195-216.

[6] Ireman T, Ranvik T, Eriksson I. On damage development in mechanically fastened composite laminates. Compos Struct 2000;49(2):151-71. 
[7] Wang HS, Hung CL, Chang FK. Bearing failure of bolted composite joints. Part I: experimental characterization. J Compos Mater 1996;30(12):1284-313.

[8] Tong L. Bearing failure of composite bolted joints with non-uniform bolt-towasher clearance. Compos Part A: Appl Sci Manuf 2000;31(6):609-15.

[9] McCarthy CT, McCarthy MA, Lawlor VP. Progressive damage analysis of multibolt composite joints with variable bolt-hole clearances. Compos Part B: Eng 2005;36(4):290-305.

[10] Valenza A, Fiore V, Borsellino C, Calabrese L. Failure map of composite laminate mechanical joint. J Compos Mater 2007;41(8):951-64.

[11] Xiao Y, Ishikawa T. Bearing strength and failure behaviour of bolted composite joints (part I: experimental investigation). Compos Sci Technol 2005;65(78):1022-31.

[12] Chen WH, Lee SS, Yeh JT. Three-dimensional contact stress analysis of a composite laminate with bolted joint. Compos Struct 1995;30(3):287-97.

[13] Riccio A, Marciano L. Effects of geometrical and material features on damage onset and propagation in single-lap bolted composite joints under tensile load: Part I - experimental studies. J Compos Mater 2005;39(23):2071-90.

[14] Thoppul SD, Finegan J, Gibson RF. Mechanics of mechanically fastened joints in polymer-matrix composites structures - a review. Compos Sci Techno 2005;69(3-4):301-29.

[15] Sen F, Pakdi M, Sayman O, Benli S. Experimental failure analysis of mechanically fastened joints with clearance in composite laminates under preload. Mater Des 2008;29(6):1159-69.

[16] Kapti S, Sayman O, Ozen M, Benli S. Experimental and numerical failure analysis of carbon/epoxy laminated composite joints under different conditions. Mater Des 2010;31(10):4933-42.

[17] Santiuste C, Barbero E, Miguelez MH. Computational analysis of temperature effect in composite bolted joints for aeronautical applications. J Reinf Plast Compos 2011;30(1):3-11.

[18] Thomas FP, Zhao Y. Torque limit for composites joined with mechanical fastener. In: 46th AIAA/ASME/ASCE/AHS/ASC structures, structural dynamics and materials conference. Austin, Texas, April 2005. p. 18-21.

[19] Ekh J, Schon J. Effect of secondary bending on strength prediction of composite, single shear lap joints. Compos Sci Technol 2005;65(6):953-65.

[20] Egan B, McCarthy CT, McCarthy MA, Frizzell RF. Stress analysis of single-bolt single-lap, countersunk composite joints with variable bolt-hole clearance. Compos Struct 2012;94(3):1038-51.
[21] Chang FK, Chang KY. A progressive damage model for laminated composites containing stress concentrations. J Compos Mater 1987;21(9):834-55.

[22] Chang FK, Lessard LB. Damage tolerance of laminated composites containing an open hole and subject to compressive loadings: part I - analysis. J Compos Mater 1991;25(1):2-43.

[23] Xiao Y, Ishikawa T. Bearing strength and failure behaviour of bolted composite joints (part II: modelling and simulation). Compos Sci Technol 2005;65(78):1032-43.

[24] Dano ML, Gendron G, Picard A. Stress and failure analysis of mechanically fastened joints in composite laminates. Compos Struct 2000;50(3):287-96.

[25] Dano ML, Kamal E, Gendron G. Analysis of bolted joints in composite laminates: strains and bearing stiffness predictions. Compos Struct 2007;79(4):562-70.

[26] Hongshuang L, Zhenzhou L, Zhang Y. Probabilistic strength analysis of bolted joint in laminated composites using point estimate method. Compos Struct 2009;88(2):202-11.

[27] Hashin Z. Failure criteria for unidirectional fiber composites. J Appl Mech 1980;47(2):329-34.

[28] Hühne C, Zerbst AK, Kuhlmann G, Steenbock C, Rolfes R. Progressive damage analysis of composite bolted joints with liquid shim layers using constant and continuous degradation models. Compos Struct 2010;92(2):189-200.

[29] Riccio A. Effects of geometrical and material features on damage onset and propagation in single-lap bolted composite joints under tensile load: part II numerical studies. J Compos Mater 2005;39(23):2091-112.

[30] Hahn HT, Tsai SW. Nonlinear elastic behavior of unidirectional composite laminates. J Compos Mater 1973;7(1):102-18.

[31] Herrington PD, Sabbaghian M. Factors affecting the friction coefficients between metallic washers and composite surfaces. Compos 1991;22(6):418-24.

[32] Collings TA. The strength of bolted joints in multi-directional CFRP laminates. Compos 1977;8(1):43-55.

[33] Mischke CR, Budynas RG. Shigley's mechanical engineering design. McGrawHill; 2008.

[34] Park HJ. Effect of stacking sequence and clampling force on the bearing strengths of mechanically fastened joints in composite laminates. Compos Struct 2001;53(2):213-21. 